Operational Limits in the National Spherical Torus Experiment

by

S.M. Kaye, M. G. Bell, R. E. Bell, D. Gates, R. Maingi, E. Mazzucato, J. Menard, D. Mueller, W. Park, S. Paul, S. Sabbagh, D. Stutman

June 2000

$\int \frac{D}{5} \sqrt{\zeta} \int \sqrt{S} \begin{aligned} & \text { PAINCETON } \\ & \text { PLABMA PHYSICS } \\ & \text { LABOAATOAY }\end{aligned}$

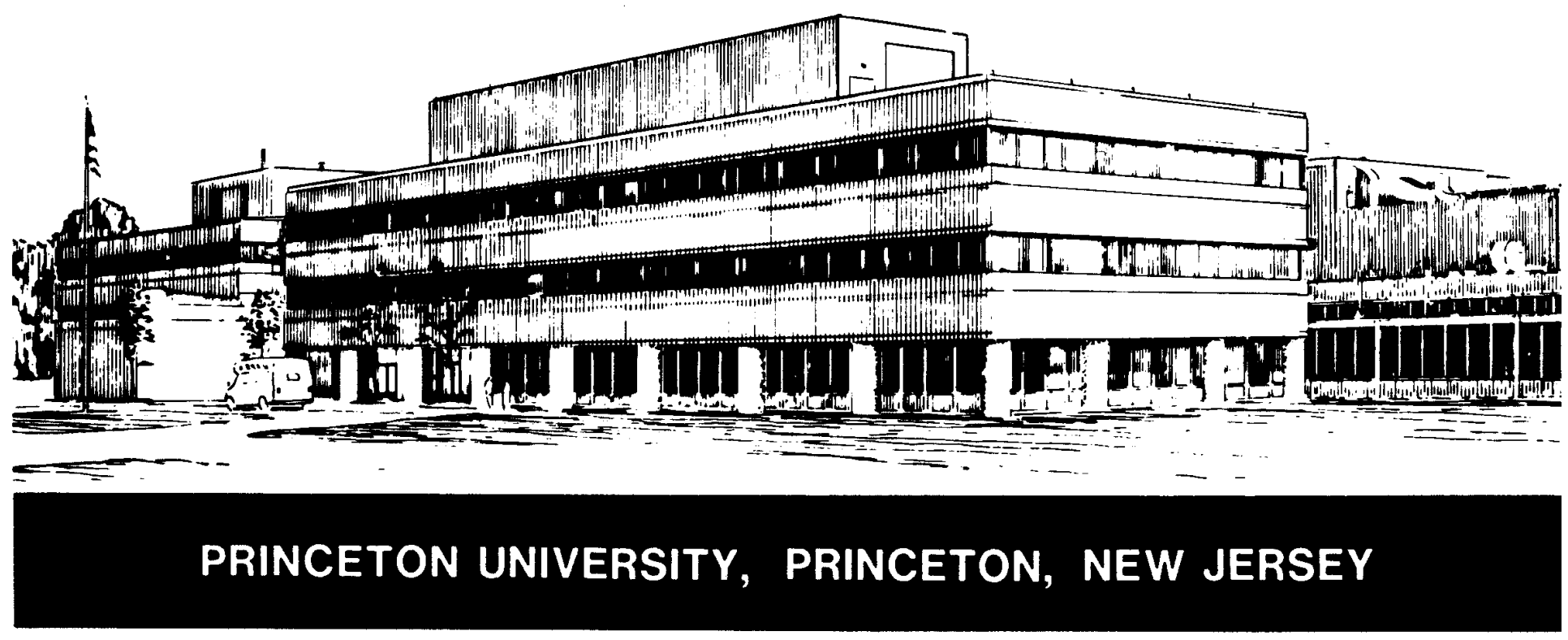




\section{PPPL Reports Disclaimer}

This report was prepared as an account of work sponsored by an agency of the United States Government. Neither the United States Government nor any agency thereof, nor any of their employees, makes any warranty, express or implied, or assumes any legal liability or responsibility for the accuracy, completeness, or usefulness of any information, apparatus, product, or process disclosed, or represents that its use would not infringe privately owned rights. Reference herein to any specific commercial product, process, or service by trade name, trademark, manufacturer, or otherwise, does not necessarily constitute or imply its endorsement, recommendation, or favoring by the United States Government or any agency thereof. The views and opinions of authors expressed herein do not necessarily state or reflect those of the United States Government or any agency thereof.

\section{Availability}

This report is posted on the U.S. Department of Energy's Princeton Plasma Physics Laboratory Publications and Reports web site in Calendar Year 2000. The home page for PPPL Reports and Publications is: http://www.pppl.gov/pub_report/

DOE and DOE Contractors can obtain copies of this report from:

U.S. Department of Energy

Office of Scientific and Technical Information

DOE Technical Information Services (DTIS)

P.O. Box 62

Oak Ridge, TN 37831

Telephone: (865) 576-8401

Fax: (865) 576-5728

Email: reports@adonis.osti.gov

This report is available to the general public from:

National Technical Information Service

U.S. Department of Commerce

5285 Port Royal Road

Springfield, VA 22161

Telephone: $1-800-553-6847$ or

(703) $605-6000$

Fax: (703) 321-8547

Internet: http://www.ntis.gov/ordering.htm 


\title{
Operational Limits in the National Spherical Torus Experiment
}

\author{
S.M. Kaye ${ }^{1}$, M. G. Bell ${ }^{1}$, R. E. Bell ${ }^{1}$, D. Gates ${ }^{1}$, R. Maingi ${ }^{2}$, E. Mazzucato ${ }^{1}$, J.

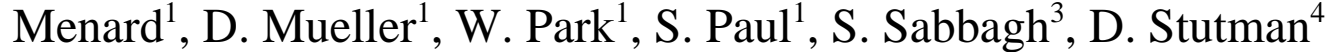 \\ ${ }^{I}$ Princeton Plasma Physics Laboratory, Princeton Univ., Princeton, N.J., U.S.A. \\ ${ }^{2}$ Oak Ridge National Laboratory, Oak Ridge, Tenn., U.S.A \\ ${ }^{3}$ Columbia University, New York, N.Y., U.S.A \\ ${ }^{4}$ Johns Hopkins University, Baltimore, Md., U.S.A
}

\section{I) Introduction}

The National Spherical Torus Experiment (NSTX) is a proof-of-principle scale device whose mission is to establish the physics basis of low aspect configurations most notably in the areas of plasma stability, transport and non-inductive current drive [1,2]. The first series of physics experiments was conducted during the period from Sept. 1999 through Jan. 2000 [3-7]. Among the first experiments was a study to map out and characterize the operational density and q-limits. Density limits have typically been associated with enhanced radiated power due to overfuelling or impurity influx [8], although ion neoclassical transport may impose a density limit at very high densities in ohmic, gas-fueled plasmas [9]. q-limits have typically been manifestations of destabilization of $m=2 / n=1$ kink or tearing modes that lead to a sudden discharge termination [8].

\section{II) Experimental Procedure}

The density and q-limit experiments in NSTX were performed in gas-fuelled ohmic plasmas with currents in the range from 0.3 to 0.6 MA, although discharges at the highest obtained current, 1 MA, were included since these discharges reached low- $\mathrm{q}\left(\mathrm{q}_{95} \sim 4\right)$. Typical discharge parameters for the density limit experiments were $\mathrm{B}_{\mathrm{T}}=0.3 \mathrm{~T}, \mathrm{R} / \mathrm{a}=0.85 / 0.68 \mathrm{~m} \sim$ $1.25, \kappa=1.8, \delta \sim 0.4, \mathrm{D}_{2}$ gas fuelling. The ohmic heating power varied from 1 to $2.5 \mathrm{MW}$. The discharges were limited by the inner wall. The line-integral density was measured by a twopass, $2 \mathrm{~mm}$ microwave interferometer, radiated power by a tangential bolometer array, and MHD activity was monitored by poloidal and toroidal arrays of Mirnov coils and by three Soft X-ray arrays for internal fluctuations. q-limit experiments were performed in similar plasmas with $\mathrm{I}_{\mathrm{p}}=600 \mathrm{kA}$.

\section{III) Density Limits}

The density limit experiments were performed in ohmic discharges with flattop currents at the 0.3, 0.4 and $0.6 \mathrm{MA}$ level. These shaped plasmas provide a good test of whether it is the Hugill or Greenwald limits that characterize the density limit, as the Greenwald limit $\left(\leq \mathrm{I}_{\mathrm{p}} / \pi \mathrm{a}^{2}\right)$ is almost a factor of two greater than the Hugill limit $\left(\leq 2 \mathrm{~B}_{\mathrm{T}} / \mathrm{Rq}_{\mathrm{cyl}}\right.$, where $\left.\mathrm{q}_{\mathrm{cyl}}=2.5 \mathrm{a}^{2} \mathrm{~B}_{\mathrm{t}}\left(1+\kappa^{2}\right) / \mathrm{RI}_{\mathrm{p}}\right)$ for the operating parameters. Gas puffing was employed during the current flattop period to raise the density. Figure 1 shows a $600 \mathrm{kA}$ discharge in which the line-integral density rises to a value of approximately $3 \times 10^{15} \mathrm{~cm}^{-2}\left(2.2 \times 10^{13} \mathrm{~cm}^{-3}\right.$ line-average). At the time of maximum density, a burst of MHD is seen to grow on an outside Mirnov coil, and the density ceases to increase. The MHD slows, locks, and shortly thereafter, at approximately $\mathrm{t}=0.23 \mathrm{sec}$, leads to a Global Reconnection Event that is responsible for loss of plasma current, stored energy, and ultimately leads to the discharge termination. There is no increase in the radiated power leading up to this density limit; as can be seen from the figure, estimates of the radiated power show levels of about $0.5 \mathrm{MW}$ remaining steady through this period, which is approximately 30 to $50 \%$ of the ohmic 
heating power. In general, the density limit so far observed in NSTX cannot be unambiguously tied to enhanced global radiation, as typically $\mathrm{P}_{\mathrm{rad}} / \mathrm{P}_{\mathrm{oh}} \leq 50 \%$ at the limit.

A decrease in the radiated power occurs at $\mathrm{t}=0.13 \mathrm{sec}$. This represents an internal redistribution of the radiated power (and probably density) profile, and it may be associated with double tearing modes associated with core impurity accumulation and a resulting double-valued q-profile. A burst of $\mathrm{m}=2$ activity is observed at on the Soft $\mathrm{X}$-ray array this time.

Fig. 2 shows the Soft Xray emission during the time of the MHD burst near $\mathrm{t}=0.22 \mathrm{sec}$ plotted as a function of spatial channel (ordinate) and time (abscissa). The SXR signals, which are sensitive to emission with photon energies from 0.2 to $1.5 \mathrm{keV}$, show a clear $\mathrm{m}=1$ snake associated with the MHD burst. The toroidal Mirnov coil array on the center stack reveals this burst to be $n=1$. All density limits encountered so far, except for the ones associated with the early profile redistribution, are characterized by growing and locking bursts of $\mathrm{m}=1$ activity. Snakes are often associated with high-Z impurity radiation; other spectroscopy qualitatively shows non-negligible levels of metallic impurities (i.e. $\mathrm{Cu}$ from some non-graphite covered passive plates [10] and $\mathrm{Fe}$ ) in the plasma. Thus it is probable that the present density limit is
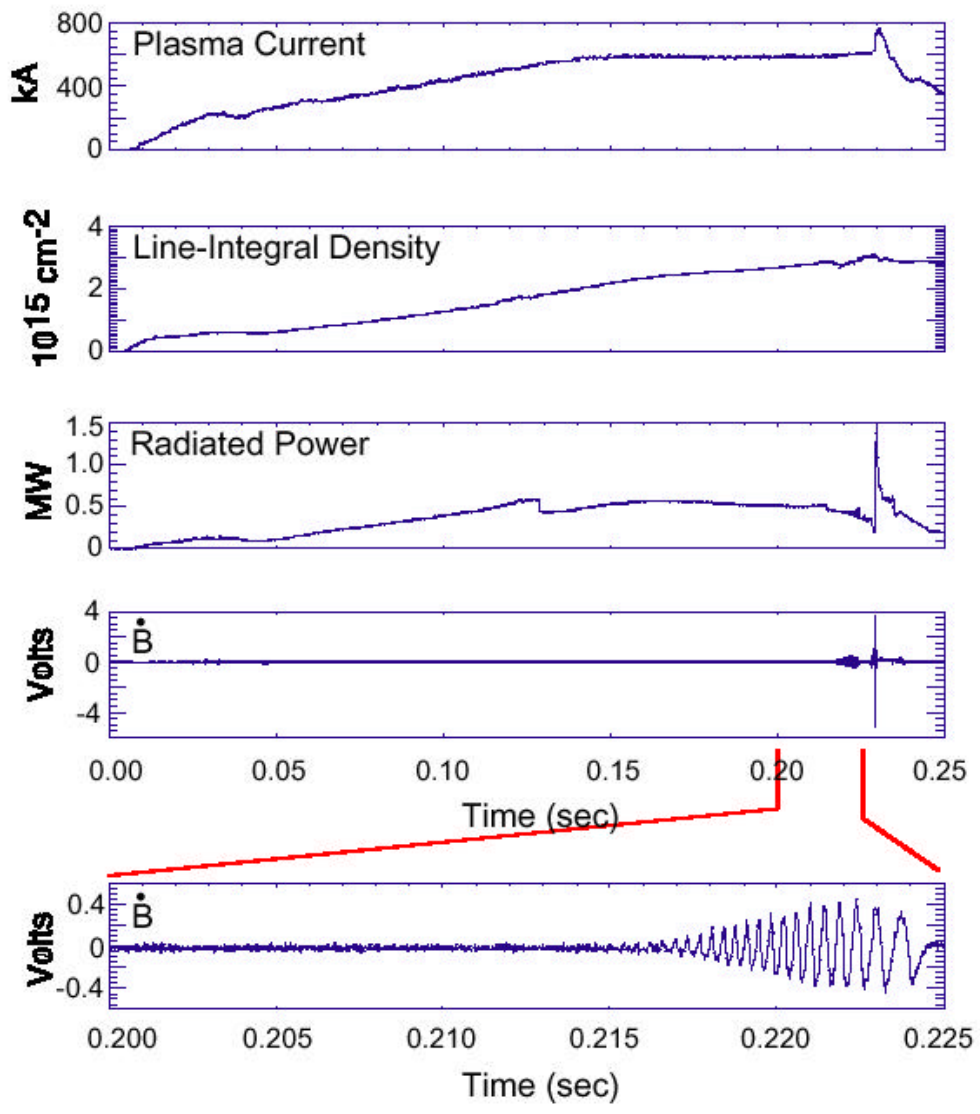

affected by the presence of metallic impurities.

\section{IV) q-Limits}

Low-q was produced by either operating at high plasma current (1 MA) or by ramping the toroidal field down to approximately half the initial level during the current flattop period. One figure of merit for these discharges is the equivalent cylindrical q-values, $\mathrm{q}_{\mathrm{cy}}$, values as low as 1.3 obtained with these methods. Fig. 3 shows the evolution of a discharge where the TF is ramped down from 0.3 to $\sim 0.15 \mathrm{~T}$ at a rate of $1.4 \mathrm{~T} / \mathrm{sec}$. MHD, as seen on the Mirnov coil, begins at approximately the same time as when $\mathrm{q}_{\mathrm{cyl}}$ passes through 2 . The MHD leads to a severe distortion of the plasma surface at $t=0.168 \mathrm{sec}$, as shown on the fast camera image, which leads to the discharge termination. The MHD fluctuations prior to the disruption are identified as $m=2$ from the SXR array, and their onset is associated with the $\mathrm{q}=2$ surface expanding out to within $10 \mathrm{~cm}$ of the plasma edge. 


\section{V) Summary}

Density and q-limits in NSTX have been explored in ohmic discharges during the device's initial period of operation. The limits are summarized in the Hugill diagram in Fig. 4, in which each line represents the trajectory in time of each individual discharge in the study. Density limits, which are associated with the growth of $m=1$ oscillations, are well described by the Hugill limit with $\mathrm{n}_{\mathrm{e}} \mathrm{R} / \mathrm{B}_{\mathrm{T}} \leq 2 / \mathrm{q}_{\text {cyl }}$, which is about $60 \%$ of the Greenwald limit for the operating parameters of the experiment. Here, the use of the lineaveraged, rather than volumeaveraged density, in the absence of density profile information, gives a

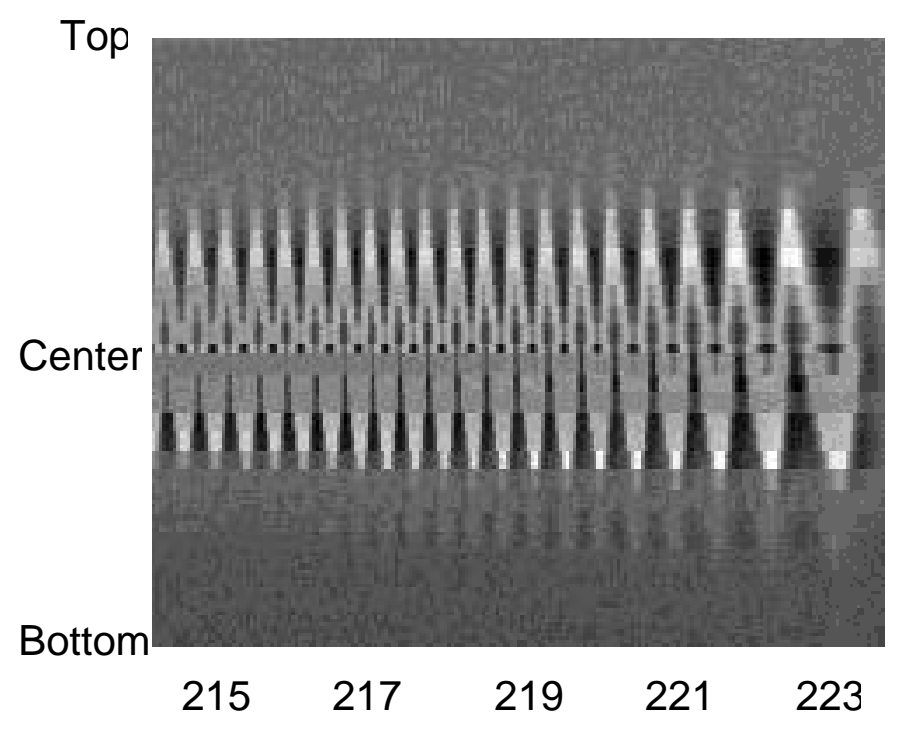

Fig. 2: Soft X-ray emissivity from horizontal arrays. Top, center and bottom are with respect to the plasma.
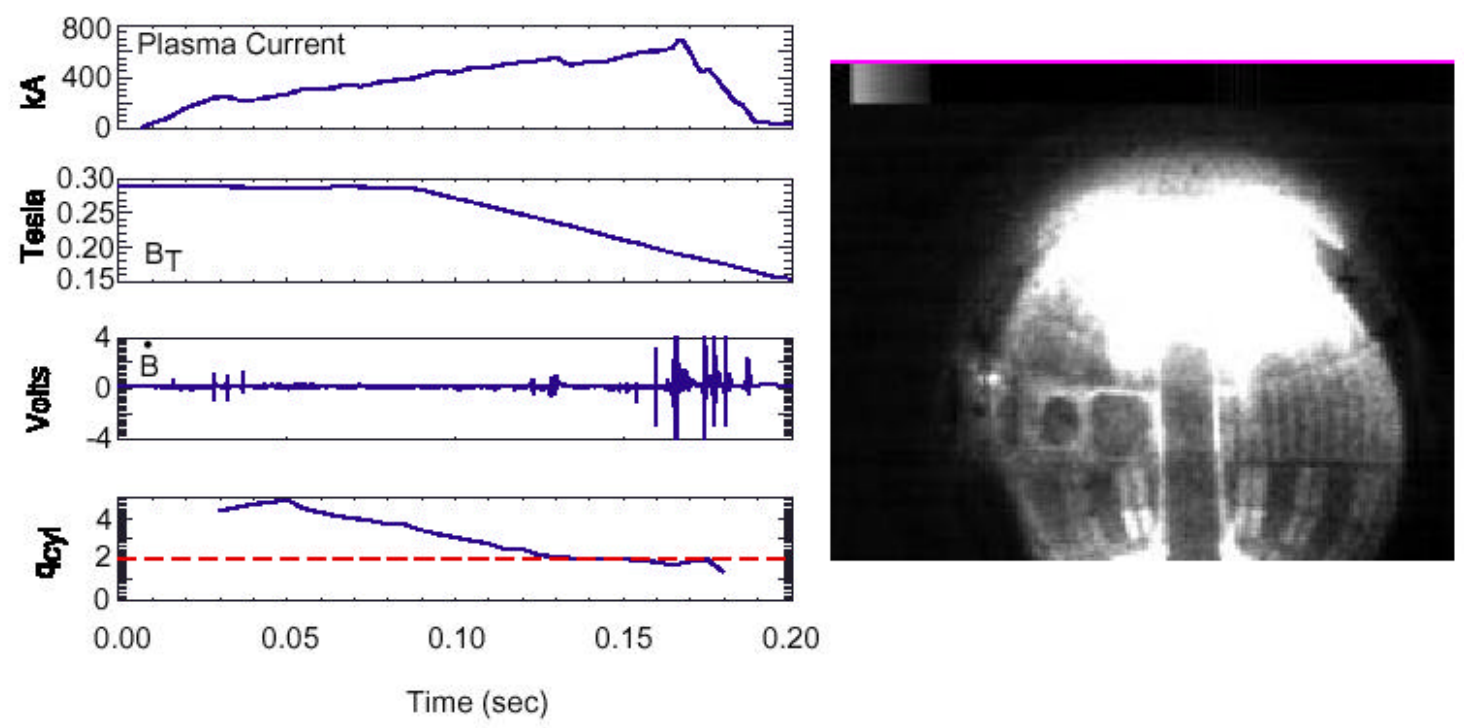

Fig. 3: Evolution of q-limit discharge (left), fast camera image of plasma at $t=0.168 \mathrm{sec}$ (right).

conservative view of the limit. As the plasma becomes cleaner (e.g., increased graphite tile coverage and boronization) and with introduction of auxiliary heating power, the observed density limit may well extend beyond the present limit. The q-limit was manifest as growing and locking 2/1 perturbations leading to severe kinking of the plasma surface and subsequent discharge termination as $\mathrm{q}_{\mathrm{cyl}}$ decreased below 2, associated with the position of the $\mathrm{q}=2$ surface expanding outward to within $10 \mathrm{~cm}$ of the plasma edge. Equivalent cylindrical qvalues down to $1.3\left(\mathrm{q}_{95}\right.$ down to 2.5$)$ have been achieved. 


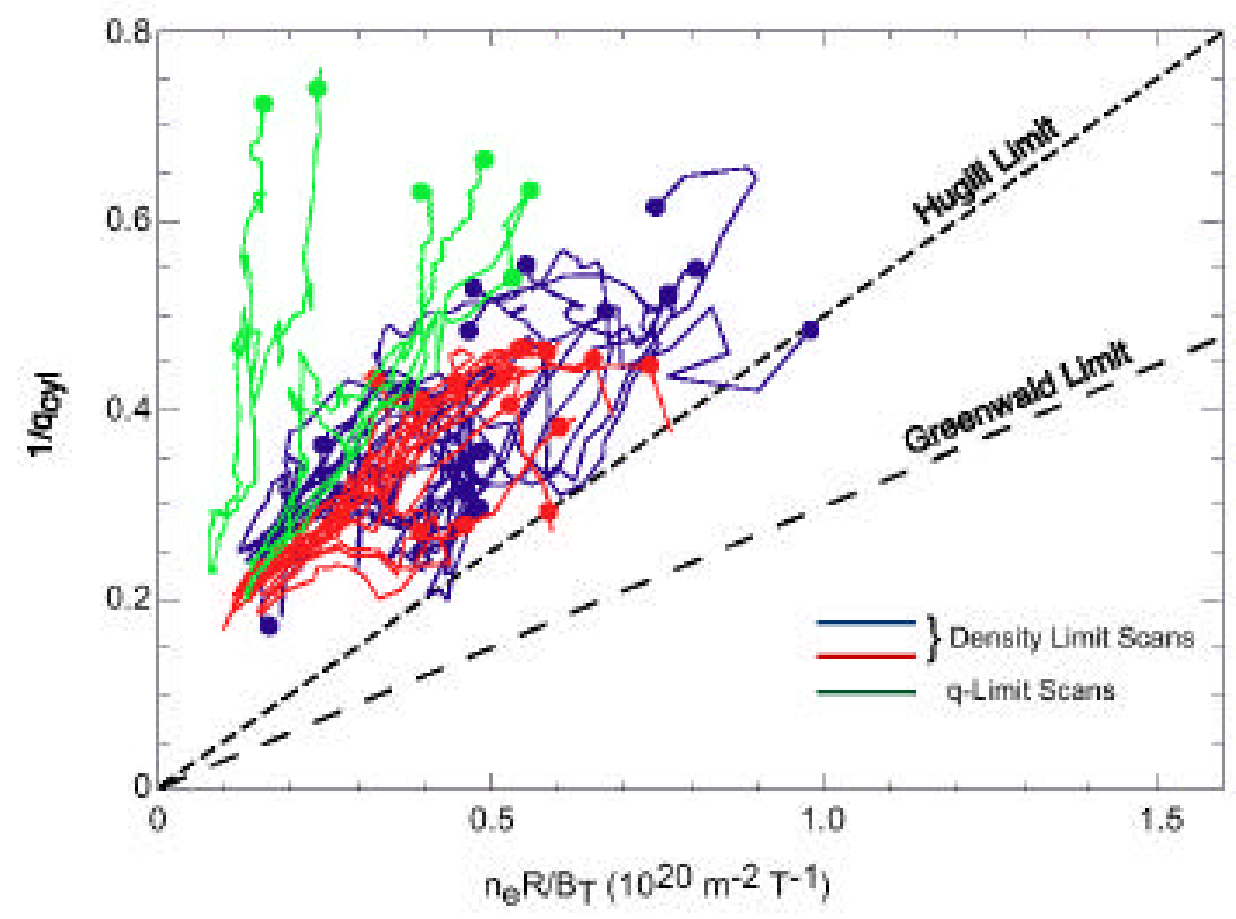

Fig. 4: Hugill diagram for density and q-limit study. Each line represents the time trajectory of each individual discharge. The dots on each trajectory indicate the last time point plotted for that discharge.

This work has been supported by U.S. DOE Contract \#DE-AC02-76CH03073 at the Princeton Plasma Physics Laboratory.

\section{References}

1) S.M. Kaye et al., Fusion Technology, 36, (1999) 16.

2) M. Bell et al., "Physics results from the National Spherical Torus Experiment", this conference.

3) D. Gates et al., "Initial operation of NSTX with plasma control", this conference.

4) J. Menard et al., "Flux consumption optimization and the achievement of 1 MA on NSTX", this conference.

5) R. Raman et al., "Coaxial Helicity Injection (CHI) for the generation of non-inductive current in NSTX", this conference.

6) S. Sabbagh et al., "Investigation of equilibrium domain in NSTX ohmic plasmas", this conference.

7) S. Zweben et al., "Visible imaging of edge turbulence in NSTX", this conference.

8) ITER Physics Expert Group on Disruptions, Plasma Control, and MHD, ITER Physics Basis Chapter 3, Nuc. Fusion, 39 (1999) 2251 and references therein.

9) M. Greenwald et al., Phys. Rev. Lett.,53 (1984) 352.

10) H. Kugel et al., "Overview of impurity control and wall conditioning in NSTX", $14^{\text {th }}$ PSI Conference, Rosenheim, Germany, May 2000. 
The Princeton Plasma Physics Laboratory is operated by Princeton University under contract with the U.S. Department of Energy.

\author{
Information Services \\ Princeton Plasma Physics Laboratory \\ P.O. Box 451 \\ Princeton, NJ 08543
}

Phone: 609-243-2750

Fax: 609-243-2751

e-mail: pppl_info@pppl.gov

Internet Address: http://www.pppl.gov 